\title{
REBUILDING LIVES: \\ PSYCHOLOGICAL TRAUMA AND GROWTH IN THE AFTERMATH OF A CATASTROPHIC AUSTRALIAN BUSHFIRE
}

\author{
LYNNE McCORMACK ${ }^{1} \&$ TAMRA SILLICK ${ }^{2}$ \\ ${ }^{1}$ University of Newcastle, Australia \\ ${ }^{2}$ University of Canberra, Australia
}

\begin{abstract}
Catastrophic natural disasters such as a 'blow-up' bushfire have the capacity to overwhelm authorities, ambush escape routes for humans and animals trying to flee, and destroy communities in minutes. They are increasing in frequency as the global temperature continues to rise. Despite the physical and material risks, such terrorising events are psychologically confronting and can leave individuals with traumatic distress, even psychopathology. However, little research explores the subjective interpretation of those who have been impacted physically, psychologically and financially by a catastrophic bushfire. The 'lived' experience of six participants was explored and analysed using Interpretative Phenomenological Analysis. Four themes emerged: surviving the terror; on patrol and guilty; no longer me/no longer us; and personal renaissance; which capture the participants' ongoing trajectory of survival, selfinterrogation, and a search for meaning and reconnection with loved ones and community. However, in the immediate period post-fire, career goals, child/parent relations, intimate relationship, and sense of community belonging were unexpectedly and negatively impacted. New perspectives were forced onto old relationships compelling these individuals to confront 'self'. Complicating recovery was a sense of betrayal at being let down, even abandoned, by first responders. Trust diminished as society quickly lost interest in their plight and it was no longer headline news. This was further compounded when financial reparation proved grossly inadequate. Slowly, acceptance of a lone journey emerged whereby the participants began to redefine life differently, examining prior roles and expectations. This positive shift in interpretation promoted positive change: increased empathy, love, and gratitude. A decade later they were able to identify that trust-in-a-future had re-emerged. This study highlights the complexity of distress and recovery for these participants and suggests community preparation and support, including financial and psychological support, is currently challenged in the aftermath of a threat that is predicted to increase in frequency in many countries.
\end{abstract}

Keywords: catastrophic natural disasters, 'blow-up' bushfires, posttraumatic stress, posttraumatic growth, Interpretative Phenomenological Analysis.

\section{INTRODUCTION}

The Climate Institute released a Policy Brief in February, 2016 reaffirming facts concerning bushfires and climate change caused by carbon and other greenhouse gas pollution. It stated:

"Extreme fire weather has increased, and the fire season has lengthened, across large parts of Australia since the 1970s ... By 2050, compared with the climate of 1980 to 1999, the number of extreme fire-weather days is projected to grow in southern and eastern Australia by 10 to 50 per cent for a low greenhouse gas emissions scenario (assumes strengthening global action to limit climate change, in line with the 2015 Paris Agreement), and by 100 to 300 per cent for high emissions (assumes greater climate change due to higher levels of carbon pollution or a climate system more sensitive to greenhouse gases). The psychological and social tolls of bushfires impose substantial additional costs on communities, aside from the physical injury from heat, flames and smoke. The cost in the treatment and lost productivity associated with 
mental disorders is already estimated at nearly $\$ 8$ billion annually. Mental health problems also tend to coalesce with economic and social ones, meaning that the overall toll is likely to be larger still" [1].

However, most of Australia's severe bushfires are preconditioned by the Indian Ocean Dipole defined by the change in temperature gradients across the Indian Ocean influencing the rise and fall of moisture and air. As such it affects the climate of Australia and other countries that surround the Indian Ocean Basin. Impact is global. Pollutants and smoke emitted from catastrophic fires in the region contribute to health problems for millions of people, and loss of economic activity. It impacts rainfall variability and is responsible for many devastating floods in East Africa, causing death and displacement for thousands of people [2].

One of the most confronting natural disasters for both citizens and essential services is a 'blow up' bushfire which tends to accelerate to staggering speeds particularly during extreme weather conditions. During drought years, when the ecosystem becomes drier and more flammable, there is a greater increase in bushfire activity. 'Blow-up' bushfires occur when two simultaneous fires collide; an already raging fire reaches an area of heavier fuel or arrives at the edge of a steep upslope; or wind change provides a sudden in-draft of fresh air to the fire. Such conditions usually result in a 'fire storm', a potentially catastrophic state of affairs where serious damage is inevitable and loss of life possible. Currently, the system devised to detect the progress of wildfires/bushfires consists of spotter planes, lookout towers, communication networks, and trained fire personnel. As rainless months go by and with the ever-increasing marrying of urban sprawl and bushland, many residential areas are ill-prepared in the face of a 'blow-up' bushfire [3].

Bushfires are part of the Australian landscape and a regular cycle in the climate estimated to have been occurring for approximately 60 million years. Its native eucalypt trees are especially prone to fire as their leaves store a highly-flammable oil. Lightning strikes are responsible for approximately $26 \%$ of all fires but unfortunately, $25 \%$ of bushfires are deliberately-lit and the second most common cause of ignition. However, the speed and ferocity at which they overwhelm communities has led to deadly scenarios. In 2009, the worst fire conditions ever recorded in the state of Victoria resulted in 173 fatalities and the destruction of more than 2000 homes. In January, 2003, fire threatened the very heart of Australia surrounding its capital, Canberra, and area of just over 2,400 square kilometres. The speed at which it descended on suburban streets caught many unaware, trapping many who stayed to battle the fire in an attempt to save their homes. Almost $70 \%$ of the Australian Capital Territory's (ACT) pastures, forests (pine plantations), and nature parks were severely damaged, and most of the renowned Mount Stromlo Observatory was destroyed. After burning for a week around the edges of the Capital, the fires descended into the suburban streets on $18^{\text {th }}$ January and over the next ten hours, destroyed more than 500 homes. Remarkably, only 4 people died [4], [5].

While the Canberra fire disaster was a complex issue, it is estimated that had a prearranged burn been conducted the cost would have been approximately \$100,000AUD and would have prevented the disaster. However, it did not occur due to a misunderstanding in land management policies. Conversely, the cost of the fire was \$257AUD million. Complicating the outcome was the proliferation of rural lifestyle into the bushland, not always actively managed with many former urbanites having little awareness of bushfire issues and the threat posed by unmanaged native vegetation [3].

The human cost is fraught with immediate and long-term consequences. Following disasters psychosocial outcomes can include specific psychological problems e.g. posttraumatic stress disorder (PTSD), other anxiety disorders and depression; physical 
health problems e.g. increased smoking and drinking, psychosomatic complaints, and social issues e.g. financial stress, perceived lack of social support, and problems specific to children and youth (clinginess, temper tantrums, separation anxiety, hyperactivity) [6]. When psychosocial support is absent, the risk of psychopathology increases [6]-[8]. Survivors' experience of bushfire is best understood through a biopsychosocial context as sensory memory from the day of the fires, mixed emotions (fear, relief), interplay of relationships in recovery, and the impact of other significant life events can impact on future wellbeing [9].

There is evidence that being a parent adds to post-disaster distress with increased levels of anxiety reported in those who are parents in comparison to adults with no children [10]. Marital stress and domestic violence may also increase post-disaster. For example, longitudinal research following the Ash Wednesday bushfires in Australia, found that within families there was an increase of conflict, irritability, and withdrawal when those families had been directly exposed to the bushfire [9], [10]. Overprotectiveness, irritability, and depression, and other trauma related symptoms can contribute to children's emotional and behavioural problems. Importantly, when all family member experience a traumatic event, there are diverse individual, subjective responses causing different recovery needs to further compound the trajectory of family cohesion post trauma [6], [10]-[12]. In particular, some individuals may withdraw into avoidant behaviours unaware that without the opportunity to narrate, memories can be triggered by unexpected occurrences resulting in involuntary arousal and fragmented flashbacks [13].

Making meaning and seeking a sense of purpose and future goals are normal responses following a traumatic experience and vital to psychological wellbeing [7]. These natural drives to seek meaning are therefore the tools that can assist growth and self-perpetuate psychological wellbeing. In fact, trauma appears to play a role in promoting positive alternate narratives by agitating a cognitive ruminative phase of sense making post trauma in veterans [8], humanitarian aid workers exposed to genocide [14]; post Southeast Asia tsunami [15], and following a terrorist attack in Bali [16]. Earlier theories of positive self-valuing combined with a nourishing environment, e.g. Rogers' [17] organismic valuing process theory and Deci and Ryan's [18] self-determination theory, have provided the foundation for growth theories including Joseph and Linley's [19] organismic valuing process theory of growth out of adversity (OVP). The OVP theory posits that there are many possible ways of dealing with exposure to stressful and traumatic experiences that may or may not lead to growth. Accordingly, when adverse situations and contexts challenge the individual, the individual response will be dependent on whether early unconditional nurturing of self-regard, and self-actualising processes have been positive or negative. Similarly, for optimum psychological wellbeing to persist, the growth process must continue to be stimulated and consciously pursued [7], [19].

Therefore, providing the opportunity for individuals exposed to a horrific 'blow-up' bushfire to explore and interpret their narrative can provide an opportunity for healing and growth and can contribution to research. Narratives sought through qualitative research can shed light on future disaster management issues and psychological care of the individual overwhelmed by events. As such, this qualitative study sought the 'lived' experience of individuals who either choose to remain and defend their homes, or were forced to flee from a catastrophic bushfire. It sought both positive and negative interpretations of events a decade after the catastrophic disaster and a deeper understanding of how these individuals redefined their lives in the context of family life, following personal threat to self and/or family members, and multiple losses including property and possessions, neighbours and neighbourhood. 


\section{METHOD}

\subsection{Participants}

Participants were six individuals ( 3 couples) aged between 49 and 55 years and were comprised of 3 men: Fred, Ron and David; and 3 women: Tracey, Rachel and Dani. All participants are de-identified. Each had experienced a catastrophic or 'blow-up' firestorm while living in the Australian capital, Canberra in 2003. The ferocity and speed caught all unaware. Each had limited warning or help from emergency services. Tracey, Fred, Rachel, Ron, and Dani were at home with their children when the bushfire first threatened. David was attempting to get home. A relative took Tracey and Fred's children to safety while they stayed with their home to fight the fire. Only when life became threatened did they abandon their home. Rachel and Ron stayed to fight the fire and never evacuated for the duration of the crisis. They kept their two small children with them. Dani and one of her children evacuated as the main fire front descended into the suburbs. Participants' children were aged between 2 and 14 years at the time of the crisis. Tracey, Fred, Dani and David, lost their homes in the fire.

Four participants received counselling. One reported being diagnosed with 'emotional blunting.' The three female participants sought out a women's support group at various times. As an idiographic study of individual experience, each participant is treated as a single unit of data in his/her own right [20].

\subsection{Procedure}

Participants were sought through community notice boards, social support groups, and internet sites for survivors of bushfires following university human ethics approval. Purposive sampling ensured all participants who volunteered for the study had experienced the same phenomena, the 2003 Canberra bushfire. Each received a study information letter, and written consent was obtained prior to interview. Interviews were held at a time and place suitable to the participant and data was collected using a semi-structured interview schedule relevant to the aims of the study. Each interview lasted approximately 1.5 hours, which allowed enough time for a reiterative exploration of the unique experiences of a bushfire. Participants were prompted for clarification as necessary. The second author conducted the interviews, and transcribed the data. Each author independently analysed the data before robust discussion led to final themes that produced the results and discussion.

\subsection{Analytic approach}

IPA [20] seeks sense making through the use of double hermeneutics promoting interpretative activity aimed at unpicking the individual's perceptions of meaning, and the researcher's attempts to make sense of these perceptions. It's primarily aim is to capture the deeper 'lived' experience and the meaning ascribed to that experience by acknowledging the participants as the experts in their own life. The researcher therefore seeks to describe rather than explain. Experiences of the past are witnessed in the present encouraged through the shared reflexivity of researcher and participant [20].

\subsection{Credibility}

Data was collected, transcribed and analysed according to the rigorous protocols of IPA to ensure trustworthiness, verification, credibility, and dependability. Rigour in qualitative 
research is addressed by adhering to the steps of the particular methodology employed underpinned by philosophical positions [20]. It is further addressed through purposive sampling of a small homogenous group, funnelling down to the phenomenon being explored with strict adherence to independent auditing prior to final thematic consensus by all researchers. Qualitative research seeks subjective interpretations of a phenomenon that is both convergent (across all transcripts) and divergent (within one transcript). Saturation is therefore extraneous to IPA [20], [21].

\subsection{Authors' perspective}

Both authors are trauma therapists and the first author a researcher, and an international delegate for the Australian Red Cross. Their backgrounds bring both insight and biases to the project actively debated at every stage of the analysis to the participant's world.

\section{RESULTS}

Four superordinate themes represent the coexisting nature of distress and growth that was experienced by the individual participants over time: surviving the terror; on patrol and guilty; no longer me/no longer us; and Personal renaissance (see Table 1). Although participants interpreted both positive and negative experiences in the decade following the fire, the trajectory of recovery unexpectedly and negatively impacted on career goals, child/parent relations, intimate relationship, and sense of community belonging. New perspectives were forced onto old relationships bringing unexpected self -awareness and the redefining of positive new goals. Quotations from the interviews were used to define and illustrate the themes.

\subsection{Surviving the terror}

\subsubsection{Sensory overload}

This subtheme highlights the sensory overload of fear and terror felt by these participants when exposed to a catastrophic bushfire. The participants' memories describe that sensory bombardment as they revisit the living energy of a firestorm:

The heat was so intense, it was just incredible heat, and you could feel the power of it as it roared around the house. It was sort of like a horror movie; every time this creature was trying to find a gap in the armour, and ah, every time you thought you'd beat it, it's at another window, or it's under the doors, or coming from upstairs. (Fred)

Their relationship with the event was interpreted as being one of sensory overload:

The sights, the sounds, the smell, the temperature - everything was just on high alert! (Rachel)

Which brought an immediate confrontation with the sensation of impending death:

I thought we were going to die ... it was getting hotter and hotter and hotter, and you're sucking this hot air into your lungs. (Rachel)

Table 1: Superordinate themes.

\begin{tabular}{ll}
\hline 1. & Surviving the terror \\
\hline 2. & On patrol and guilty \\
\hline 3. & No longer me/no longer us \\
\hline 4. & Personal renaissance \\
\hline
\end{tabular}


Alone without outside contact, and cut off from communication with authorities, their imagination found other knowledge with which to compare the frightening triggers all around them:

It was just like a war zone! ... like bombs going off ... and the noise, the noise was like a jet engine (voice quivering), it was deafening ... and I said I think the smoke's going to kill us, and we were having trouble breathing. (Tracey)

Yet these comparisons left them little recourse of action and actively reliving the feelings of helplessness while striving to make sense of the events and their responses:

We heard these explosions first ... houses just exploding (crying, head in hands) ... and it just kept happening! (Ron)

\subsubsection{Helpless protector}

Momentary decisions were remembered as having set a course in action that defined their own and their children trajectory of no escape:

All the electricity had gone off, so we couldn't get either of the cars out! (Dani)

Unable to protect their young children, memories of helpless protector were heightened for Ron and Rachel as they recalled 'the kids were inside screaming' (struggling to talk), and at this late stage of the fire's progression, any attempts at help from others 'were blocked by the police anyway' (Ron).

\subsection{On patrol and guilty}

\subsubsection{Emotional toll}

This subtheme captures the emotional toll of living through a catastrophic bushfire. In the early months after the fire, participants spoke of a subconscious, alert self always on patrol. On the night of the fire, Rachel described a sense of being in 'post trauma shock/anxiety' as she wandered up and down the street in a daze:

I just couldn't sleep at all ... it was a very long night. (Rachel)

Tracey reflected on her inability to manage her emotional responses as if a whole-of-body memory of events inhibited resolution keeping her hyperalert to every trigger:

It was a completely irrational thing, my body just started shaking uncontrollably and I started crying and I couldn't stop crying, and I knew it was OK but it was like this stored memory in my body. (Tracey)

Ron accepted that the ongoing emotional impact of the bushfire was a significant legacy in his life:

On one hand, it would be good not to remember; on the other hand, it would be a (very emotional, struggling to talk) tragedy to forget. Yeah, it would be a tragedy to forget about that, so I hope I don't. (Ron)

However, Rachel did not interpret events as significantly memorable but to be compartmentalised as if they had never happened. She described her family as 'pretty badly scarred' and the events surrounding the fire as negatively intrusive in their lives:

I'd like to put that part of our lives into a box and sort of file it away, and forget about it. (Rachel) 
Dani described a strong sense of 'before fire time and after fire time' with an impending doom about the future:

I'm not that calm about what might lie ahead. I don't have this feeling that all the bad stuff's behind us. (Dani)

\subsubsection{Infiltration of guilt}

The impact of this traumatic experience was perceived by the participants as having changed family patterns and emotional confidence. Lasting guilt infiltrated the long-term narrative of all participants. Some had been unable to protect their children from harm, some felt emotionally inadequate to meet their children's emotional needs during and after the bushfire. Plagued by unanswerable questions, ten years after the event, Ron continues to reflect; 'did we do the right thing' by choosing to remain at home and potentially traumatise our children and risk their lives:

It still worries me, you know, in 5 years or 10 years' time, something will come back from that, about making them stay ... I don't know what harm, if any, it might have done to them or affected them somehow. (Ron)

Rachel described her children as 'more clingy' in the aftermath and needing reassurance. A decade later, Ron and Rachel felt a strong need to take time with the kids, with Ron recalling how in the early days 'we just moved around like a pack'. Decisions to remain and fight the fire rather than leave with the children, constantly plagued Ron's sense making:

I wasn't anywhere meeting their needs at that time, (soft voice) they were so terrified, they screamed and cried. (Ron)

Guilt was felt as a permanent scar on parent/child relationships post fire. Ron interpreted his response to this insidious infiltration of guilt as causing preoccupation with self-distress resulting in emotional absenteeism - 'There were a couple of times I should have done things and I didn't, and I regret that'; while Rachel regretted her lack of insight into the vicarious risks to children through story-telling - 'they were hearing us tell this story of how we nearly died, and how we got trapped, and the house was on fire over and over and over again, which they didn't need to hear'.

\subsection{No longer me/no longer us}

\subsubsection{Alone and invalidated}

This subtheme highlights the discord in relationships, work and community life in the aftermath of a traumatic bushfire. Unexpected responses from authorities and community members not affected and able to move on more quickly clashed with the overwhelming loss experienced by those who lives and property were taken by the fire. Layers of loss unravelled including loss of innocence in the belief that essential services are always able to protect. "Surely the fire engine will come?" During the interviews, it was as if the participants had new moments of revelation around the swiftness of the firestorm and the aloneness of their situation:

There was no help ... we didn't see any police or fireman at any stage until, well, we never saw them full stop! ... that's the biggest shock of all, that we were on our own! (Ron)

Dark days of personal crisis led to periods of anger and resentment being felt by all six participants: 
How bitter and twisted you become about 'no sirens, no contact!' (Ron); I can't say that I never feel resentful, because I do. (Dani)

Emotionally depleted and struggling to comprehend events, immediate expectations to deal with paper work and insurance claims felt cumulatively abusive:

They put pressure on you, how long you've got to re-build, three days after the fires they expect you to respond and you just think, 'You bastards!' (David)

\subsubsection{Disconnection with past self}

Four participants lost their homes in the fires and struggled to come to terms with 'losing everything all at once ... 'every photo'. Possessions that held sentimental value and connection to the past were lamented:

My mother had given me her father's cuff links ... lost ... (very emotional) they're the emotional connections you have, even though it's a physical thing, it's that memory, it's that reminder of who they were and what they meant. (David)

For some time, Dani felt she could not make 'the right decisions anymore'. Having lost everything, the gift of others' clothing left her feeling disconnected with self:

It must be something to do with identity. It didn't look like me when I saw myself in the mirror - that wasn't me! (Dani)

The resulting insecure disruption to the family unit was a physical loss of safety and security which brought delayed emotional detachment and withdrawal. For David, the 'internal conflict' intensified several years after the fires:

I closed in, I stopped feeling ... five years later, after the fires, it was harder then than it was at the time of the fires. (David)

This delay had consequential impacts on lives and work. Ron 'lost it and he just fell apart'. $\mathrm{He}$ described becoming an observer at work. All participants reported periods of fragmentation in their relationship with their spouse:

I didn't know which way I should look at him, or what I should say, because nothing was right for him. (Rachel)

Tracey, Rachel, and Dani found that their partners all had difficulty engaging in the narrative of the fire, leading to discord in their relationships and a barrier to closeness. Years after the fire, David was diagnosed with 'emotional blunting' blocking emotional expression, causing marital conflict and the threat of separation:

It wasn't that I'd stopped loving her, it was just that I had stopped showing, expressing myself. (David)

Unexpressed emotions lead to periods of anger and frustration in intimate relationships:

It was a massive impact on who we are, or what we were at the time, and who we are and what we are now. (Fred)

All pondered with disappointment on the 'huge financial setback' of the fires and ignorance of others perception of miniscule loss. Empathy and compassion, though initially experienced, dissolved as others moved on. Tracey sensed 'thoughtlessness' in former neighbours and retreated from a 'lack of compassion and understanding'. Dani similarly withdrew disappointed in expectations from others in her community:

Everybody else thinks that you should be fine now! You know, it's over, and it's not! (Dani) 


\subsection{Personal renaissance}

This theme captures the search for purpose and meaning and gradual realisation of positive gains despite the horrors of a 'blow-up' bushfire. For some, the interview afforded the first opportunity to consider both positive and negative outcomes:

I probably expressed it at the time as, 'It took away the future', but it didn't actually take away the future, it just changed what we thought might have been the future. (Dani)

\subsubsection{Self-responsibility, empathy and love}

A renewed engagement with self-responsibility allowed a shift away from anger and blame:

As individuals ... it's about self-responsibility really. (Ron)

Dani found meaning by helping her children conceptualise the experience 'in positive ways', and in her parenting, used the fire as an opportunity to demonstrate 'patience, endless unconditional love, and living by example' to facilitate positive change in the family. Existential questions around 'what makes a good life' were also re-evaluated after the fire, with a sense of urgency being felt by participants to 'live life as full as you can' and ensure 'what we have in the here and now is good'. Over time, participants found meaning by redefining the experience as an opportunity to take a new direction in life:

It's given me a lot more sympathy and empathy as a person for what other people go through, and you never know what other people have gone through or are going through.

(David)

\subsubsection{Redefining strengths and purpose}

Seeking purpose and meaning brought personal benefit from the experience:

Well, we've got a new direction - we've got to go with it! ... It has forced me to go and do other things. (David)

Tracey found a greater sense of purpose as a result of living through the bushfire, and in the process of redefining her role in life, described wanting to draw on her experience to 'make a difference' and help others 'see their strengths'. With the passage of time, Ron found meaning through adversity by redefining the experience as a lesson in life and an opportunity for personal growth:

I think you can go through life and have a set of very narrow experiences, and that I think confines who you could possibly be. But I think the more diverse the experiences you have ... It helps people grow. (Ron)

Dani found purpose and meaning by completing a higher degree in the years after the fire, something she had always aspired to and 'wasn't prepared to put things off anymore'.

\subsubsection{Reconnecting}

Despite David's experience of 'emotional blunting' in the years after the fires, the process of reconnecting 'with the male friends I have now' has grown through greater emotional expression. The process of redefining and reconnecting led all participants to reflect on 'what's important?' in life. Having their lives, the lives of loved ones, property, and possessions threatened or taken by a catastrophic blow-up bushfire was a pivotal moment for all participants.

We're probably not as materialistic ... home is who lives here. (Ron) 
Finding support in relationships with other women and 'talking everything through' was particularly important in helping Tracey, Dani, and Rachel process thoughts and feelings and move out of adversity towards growth:

I think having some wonderful friends that I could verbalise my feelings to, that was fantastic support for me. (Rachel)

\subsubsection{Self awareness}

These participants found joy in new found self-awareness feeling 'comfortable in my own skin!' Revelations occurred within the interview:

I didn't expect to get to 53 and lights turn on! (David)

Nine years after the bushfire, David recognised the experience as a catalyst:

I think it was a catalyst to resolve those things for me. Rather than be wishy-washy about

it, I'm going to take a stand on that and be opinionated about that. (David)

There was a redefining of earlier experienced resentment with gratitude emerging over small and large acts of generosity and support from others to help them rebuild their lives:

We came back a week later to this house that was completely furnished, to the level of detail of scissors and sticky tape, pens, beds for the kids, toys for the kids, clothes in every wardrobe, a fridge with food in it! Like unbelievable! (Tracey)

Living through a catastrophic blow-up bushfire also led participants to reflect on personal strengths that were put to the test both during and in the aftermath of the crisis. Both Rachel and Dani declared they are both stronger women for the experience impacting their role as mother. Fred described a sense of being able to cope with more as a result of living through the crisis:

If something goes bad which you once upon a time would think - that's a pain in the arse

- well, so what! That's a trifle! (Fred)

Meaning was also found through a greater sense of connection to spirituality and the innate good of humankind:

Well, actually if I'm really honest, to me the whole thing was a huge spiritual awakening. (Tracey)

David expressed that a great sense of connection to others had become important to him since the fire:

I'm not a religious person ... but ... that human connection for me - that's grown, that need to experience life with friends ... family and friends ... It's a real necessary thing. (David)

and

It reinforced the fact that, as an intrinsic belief, that people will do the right thing by each other if given the chance. (Ron)

In reflecting on the positive change and growth within the family unit Rachel and Dani noted that empathy and compassion had grown and a willingness to reach out to others in need with the reflection: 'What can I do to help?'

\section{DISCUSSION}

This study highlights the independent and coexisting nature of distress and growth as these participants struggled to make meaning of being caught in one of the most unexpected and terrorising 'blow-up' bushfires to encroach a major Australian city. The traumatic events were revisited and re-interpreted through new lenses as the reiterative and double 
hermeneutic strengths of IPA sought to clarify each nuance and consideration. It provided the opportunity for the participants to explore their trauma narrative and reconsider a psychosocial journey that is continually evolving. Despite time, emotions were still raw stimulating further reflective interpretation for these participants.

Three themes represent the impact of the sensory overload that battered these individuals as they experienced the horrific event and led to a fragmentation of former beliefs and values related to relationships, community and career in the years following the fire. Guilt dogged their recovery as they variably sought to understand their actions and decisions at the time and how these had impacted their role in the workplace and as parents and partners. They initially made no sense of why or how they had survived and usual style of coping unexpectedly and negatively impacted on recovery. All expressed aloneness and immense disappointment in the unfolding of what felt like invalidation and lack of compassion by authorities, essential services, and the wider community. Consequently, in the aftermath of the fire, each began a journey of disconnection with past self in a struggle to make meaning of the future. Over the years, this struggle brought a personal renaissance depicted in the fourth theme that has emerged for these participants.

Uniquely, this study reveals the complexity of exposure to catastrophic bushfires in that these participants experienced primary trauma and vicarious trauma. They either stayed with other family members and together witnessed each other's distress, or were separated and reunited with children not knowing the fate of each other. Within the themes, on patrol and guilty and no longer me/no longer us, loss overshadows every aspect of former life. For example, each spoke of the loss of predictability, the burden of their own psychological distress, and a perceived lack of empathy and support from society, causing detachment from those in their immediate community and impacting on relationships.

At a personal level, guilt overlaid loss as they questioned momentary decisions on the day of the fire, and their capacity to fulfil predefined roles in the aftermath of the fire. Time entrenched a sense of aloneness and partner and family cohesion continued to splinter as these individuals struggled to find a path through which to reconnect and support children's needs post traumatic event while struggling with their own psychological distress. They each relayed a sense of helplessness and regret at their inability to give the emotional support their children needed in the early years, post event, with consequential loss, self-doubt and guilt still a heavy burden years after the event.

For these participants, the narrative of their family had been powerfully changed. In this context, family cohesion had been forced apart, and similar to the findings of McFarlane et al. [11] findings following the Ash Wednesday fires, marital conflict, competing priorities, different coping styles all contributed to emotional distance complicating intimate relationships and parenting of children who had variously experienced their own traumatic distress. Compounding the loss was financial set-back that made re-building shattered lives complex and without direction.

At a community level, grief, disappointment, and loss were easily re-ignited and they spoke of feeling betrayed by emergency services. Despite acknowledging the speed of events, and the difficulty in reaching safety, time had not diminished their sense of disappointment and all six participants expressed current feelings of anger and resentment toward authorities. For these participants, immediate and ongoing psychosocial support was perceived as absent remaining a strongly imbedded sensory memory in their narrative. Similar to other studies, this placed them at risk of future significant events impacting wellbeing and recovery [6], [13].

However, findings from this study reveal psychological growth is possible in the aftermath of a catastrophic bushfire. Similar to recent studies with veterans and [8], [22], and 
humanitarian personnel [14], a personal renaissance occurred for these participants through a cognitive struggle to engage differently with the world and self. As such, the participants experienced a re-emergence of empathy and love for moving forward positively. However, new to the literature is the domain of self-responsibility as a positive outcome in the aftermath of trauma, which appears to have created an intrinsic shift from anger and blame to greater self-awareness and a willingness to reach out to others in need. By moving from anger and blame, they acknowledged their right and responsibility to seek meaning in their own lives. Accepting their own capacity to embrace psychological wellbeing following this catastrophic event, recovery and growth could emerge and continue to be nurtured from a healthy selfregard and ongoing self-actualisation [7], [17], [18].

Time impacted recovery for the men of this study who were less inclined to seek psychological support than the women and delaying sense making for the men. The women found meaning by seeking out other women early with whom they could share thoughts and feelings, facilitating the process towards positive change and growth. Expression of emotions [7] and validating social support [8], [14] are posited as two important factors for promoting positive psychological change, however the men of this study had not initially sought support. In fact, David expressed his resistance to seeking help and acknowledged that the interview was the first time he had allowed memories to flood into consciousness. Early research suggests that growth may be still possible without validating social support [8]. Future research is needed to clarify to role of social support over time in facilitating posttraumatic growth.

\subsection{Limitations}

Participants' accounts of historical details were retrospective likely to be impacted by memory bias and time. Furthermore, as with all qualitative research, this study did not seek to provide a generalised summary of events specific to the Canberra bushfire nor cause and effect. However, it offers unique and clinically relevant information, and opportunities for lessons learned in supporting such individuals.

\subsection{Conclusions}

This study provided a breadth of interpretation over a decade concerning the subjective experience of a catastrophic bushfire for these participants that threatened life, family, and possessions. It has highlighted that despite horrific and complex traumatic distress, individual recovery and growth is not limited by time, gender, or coping style but can be facilitated, sometimes through social support, and sometimes through a self-perpetuating personal struggle that arises from self-responsibility, self-awareness, and a renaissance of new, future directed perspectives. However, not seeking support appeared to delay that renaissance for the men of this study who acknowledged a reticence to seek psychological support. The early sharing of narratives that promoted reiterative exploration of meaning, allowed the women to move forward more quickly in their personal renaissance and future hope. Furthermore, the opportunity for healing at the community level should be encouraged following such devastating events. By sharing narratives, communities and first responders can achieve a platform for reconciliation, re-assert commitment to the common good, and discuss future policies out of lessons learned. Additionally, therapists working with those exposed to catastrophic events are well placed to promote the ongoing reflectivity that allows the coexistence of distress and growth over time that nurtures psychological wellbeing in the individual journey following traumatic exposure. 


\section{REFERENCES}

[1] The Climate Institute, A Climate of Suffering: The Real Costs of Living with Inaction on Climate Change, 4. http://www.climateinstitute.org.au/verve/_resources/tci_aclimate ofsuffering_august2011_web.pdf. Accessed on: 18 Jan. 2017.

[2] Cai, W., Santoso, A. \& Wang, G., 2015-16 is shaping up to deliver a rollercoaster from strong El Niño to La Niña. The Conversation. http://theconversation.com/2015-16-isshaping-up-to-deliver-a-rollercoaster-from-strong-el-nino-to-la-nina-46135. Accessed on: 20 Jan. 2017.

[3] CSIRO and The Bureau of Meteorology, State of the Climate 3, 2014. http://www.bom.gov.au/state-of-the-climate/2014/. Accessed on: 15 Jan. 2017.

[4] Palenzuela, K., ABC Environment 12 Jun. 2014. http://www.abc.net.au/environment/ articles/2014/06/12/4023302.htm. Accessed on: 18 Jan. 2017.

[5] Lucas, C., Hennessy, K., Mills, G. \& Bathols, J., Bushfire weather in Southeast Australia: Recent trends and projected climate change impacts. Consultancy Report prepared for The Climate Institute by Bushfire CRC, Bureau of Meteorology, CSIRO Marine \& Atmospheric Research, 3, 2007.

[6] Norris, F.H., Friedman, M.J., Watson, P.J., Byrne, C.M., Diaz, E. \& Kaniasty, K., 60,000 disaster victims speak: Part I. An empirical review of the empirical literature, 1981-2001. Psychiatry, 65, pp. 207-239, 2002.

[7] Joseph, S., What Doesn't Kill Us: The New Psychology of Posttraumatic Growth, Basic Books: New York, 2011.

[8] McCormack, L. \& Joseph, S., A lone journey of psychological growth in aging Vietnam veterans: Redefining shame and betrayal. Journal of Humanistic Psychology, 54(3), pp. 336-355, 2014. http://dx.doi.org/10.1177/0022167813501393.

[9] Citraningtyas, T., Macdonald, E. \& Raphael, B., Disaster experience in the context of life: Perspectives five to six years after the 2003 Canberra Bushfire. Journal of Emergency Primary Health Care, 8, pp. 1-9, 2010.

[10] Solomon, S., Bravo, M., Rubio-Stipec, M. \& Canino, G., Effect of family role on response to disaster. Journal of Traumatic Stress, 6, pp. 255-269, 1993. http://dx.doi:10.1002/jts. 2490060208.

[11] McFarlane, A.C., Irwin, C. \& Policansky, S.K., A longitudinal study of the psychological morbidity in children due to a natural disaster. Psychological Medicine, 17, pp. 727-738, 1987. http://dx.doi:10.1017/S003329170002596.

[12] Pynoos, R.S., Steinberg, A.M. \& Piaentini, J.C., A developmental psychopathology model of childhood traumatic stress and intersection with anxiety disorders. Biological Psychiatry, 46, pp. 1542-1554, 1999. http://dx.doi:10.1016/S0006-3223(99)00262-0.

[13] Brewin, C.R., Dalgleish, T. \& Joseph, S., A dual representation theory of posttraumatic stress disorder. Psychological Review, 103, pp. 670-686, 1996.

[14] McCormack, L. \& Joseph, S., Psychological distress and growth in humanitarian aid personnel: Making meaning of occupational exposure to war and genocide. Community, Work, and Family, 1, pp. 1-17, 2012. doi.org/10.1080/13668803.2012.735478.

[15] Lindgaard, C.V., Iglebaek, T. \& Jensen, T.K., Changes in family functioning in the aftermath of a natural disaster: The 2004 Tsunami in Southeast Asia. Journal of Loss and Trauma, 14, pp. 101-116, 2009. http://dx.doi:10.1080/15325020802537138.

[16] McCormack, L. \& McKellar, L., Adaptive growth following terrorism: Vigilance and anger in the aftermath of Bali bombings. Traumatology, 21(2), pp. 71-81, 2015. http://psycnet.apa.org/doi/10.1037/trm0000025.

[17] Rogers, C., Toward a modern approach to values: The valuing process in the mature person. The Journal of Abnormal and Social Psychology, 68(2), pp. 160-167, 1964. 
[18] Deci, E.L. \& Ryan, R.M., Intrinsic Motivation and Self-Determination in Human Behaviour, New York: Plenum, 1985.

[19] Joseph, S. \& Linley, P.A., Positive adjustment to threatening events: An organismic valuing theory of growth through adversity. Review of General Psychology, 9, pp. 262-280, 2005. http://dx.doi:10.1037/1089-2680.9.3.262.

[20] Smith, J.A., Flowers, P. \& Larkin, M., Interpretative Phenomenological Analysis: Theory, Method, and Research, SAGE: London, 2009.

[21] Tashakkori, A. \& Teddlie, C., Integrating qualitative and quantitative approaches to research. Handbook of Applied Social Research Methods, 2nd ed., eds Rog and Bickman, SAGE: Thousand Oaks, CA, 2009.

[22] McCormack, L. \& Ell, L., Complex psychosocial distress post deployment in veterans: Reintegration identity disruption and challenged moral integrity. Traumatology, 2017. http://dx.doi.org/10.1037/trm0000107. 